http://www.inass.org/

\title{
Research of Synthetical Optimization Design System of Micro-components Based on RST and GA
}

\author{
Gong Xiaoyan $^{1,2 *}$, Xue $\mathrm{He}^{1}$, Jiang Pingy ${ }^{2}$ \\ ${ }^{1}$ School of Mechanical Engineering, Xi'an University of Science and Technology, Xi-an, P.R.China \\ ${ }^{2}$ CAD/CAM Institute, School of Mechanical Engineering, Xi-an Jiaotong University, Xi-an,P.R.China \\ * Corresponding author's Email: gongxymail@163.com
}

\begin{abstract}
The importance of synthetical optimization design for micro-components is continuously increasing with the development of MEMS, we present a new solution for synthetical optimization design by combining virtual prototype (VP), finite element method (FEM), rough set theory (RST), regression analysis (RA) and genetic algorithms (GA) in this paper. The VP and the FEM are used to design and analyze dynamic properties of coupled-energy-domain of abundant instances to obtain the data of variable, and the RST and the GA are used to confirm the variable number and restriction condition in synthetical optimization model; the RA and GA are adopted to establish the synthetical optimization model and obtain the optimal results. Meanwhile, the corresponding prototype system software of synthetical optimization design for micro-components is developed and applied to the synthetical optimization design of thermal actuated micro-pump to demonstrate the above new approach and prototype tools.
\end{abstract}

Keywords: U micro-component; VP; FEM; RST; GA; RA; synthetical optimization design

\section{Introduction}

The micro-component research originated in the 1970s, and since then, the different kinds of the micro-components, such as multi-crystal silicon gear, spring and micro-pump, have been developed and reported. However, how to optimize synthetically design for micro-components has been puzzling designers and technicians continuously for a long time. Currently, because of the severe absence of experience and formulae, the research on optimal design for micro-components is mainly limited to the analysis and the modification of the individual parameter of micro-components or the provision in the computational environments for optimization of MEMS. For example, M. Shavezipur in University of Waterloo in Canada presented a design opti- mization for MEMS tunable capacitors to maximize the production yield ${ }^{[1]} ;$ P. Schneider in Fraunhofer Institute of Integrated Circuit in Germany put forward a module-based approach for simulationbased optimization of MEMS ${ }^{[2]}$; Z. Juneidi in University of Pittsburgh in USA developed the software for MEMS synthesis and optimization ${ }^{[3]}$; S.E. Lyshevski in Purdue University in USA mainly studied the integrated structures, modules and control mechanisms of $\mathrm{MEMS}^{[4]}$; M.F. Aly in McMaster University in Canada used the finite element model to evaluate the cutting forces required to machine a silicon wafer by different cutting parameters ${ }^{[5]}$; A.Atthew in University of Colorado in US presented a reliability-based analysis and design optimization framework and embedded a First-Order Reliability Method (FORM) 
into a design optimization procedure ${ }^{[6]}$; H.li in National University of Singapore presented a variation of local point interpolation method for meshless analysis of MEMS devices and proved it was very efficient and accurate ${ }^{[7]}$. But realizing their synthetical optimization design of micro-components is still a bottleneck. Currently the optimal design of micro-components still relies on the manufacture-based fragmentary experience and simulation-based optimization design of individual parameter, the lacks of theories, rules, methods and applications of the synthetical optimization design result in design blindness and the low reliability of micro-comments.

In order to deal with the above-mentioned problems, authors put forward a combine virtual prototype (VP), finite element method (FEM), rough set theory(RST), regression analysis (RA), genetic algorithms(GA) to implement the synthetical optimization design of the micro-components and then develop the corresponding prototype software in this paper. As a new field, the basic information is quite short in the micro-component research and development, which need special experiment devices and high cost and long time. Therefore, the virtual prototype and FEM method are introduced to obtain the information in this research. A lot of instances of the micro-components are worked out by the virtual prototype method and the dynamic properties of a lot of instances are analyzed by ANSYS, and then the information for the lack problem in the synthetical optimization design of the micro-components can be settled. After the information is obtained, it needs to be synthetically disposed to obtain the reduction attributes and design rules. Because of the preparative knowledge lack of expert-based experience, it is some limitations that the information is disposed by the traditional methods such as Probability Stat. and Illegibility Gathers methods. RST possesses the abilities of pertinence lookup, redundant attributes deletion and rules acquirement ${ }^{[8]}$, and the information can be disposed and satisfactory results can be acquired by the RST and GA. On the basis of information obtained, RA and GA are adopted to realize the synthetical optimization design of the micro-components.

\section{Method of synthetical optimization design for micro-components}

\subsection{Method and functional modules of system}

The method and functional modules of synthetical optimization design for the micro-components are illustrated in Figure 1, which is described as follows:

1) Firstly, a lot of instances designed of the micro-components are collected and instances classification tree is formed, based on function demand drive method. Based on instances classification tree, object-oriented prototype model can be established, which can be used to provide the information for virtual instances design, FEM analysis, design rule acquirements and optimization model establishment.

2) Secondly, the realization process of the dynamic properties of the coupled-energy-domain of the micro-components are established based on FEM and the APDL programs of the typical micro-components are developed which can be used to the repetition analysis of the virtual instances to acquire the data of target variable.

3 ) Then, the RST and the GA are adopted to dispose the information from virtual design instances and dynamic analysis results. During this procedure, a method of the RST GA-based is used to implement attribute reduction and a coalition reduction method of RST is used to realize the acquirements of design rules.

4) Finally, the multi-regression analysis is carried out to establish the synthetical optimization model, in which the statistic data is derived from the information of virtual design instances and dynamic analysis results, the number of variable are confirmed by reduction attribute and restriction condition of variable are limited by the design rules and process technology, and at same time, GA is adopted to acquire the synthetical optimization design results.

\subsection{IDSS architecture of system}

IDSS is adopted to support synthetical optimization design process of micro-components. Through the model object reasoning and quantitative computing, the final optimal design results can be obtained. The architecture of IDSS consists of all kinds of 
enabling systems integrated into man-machine interactive interfaces, task-flow control mechanism, knowledge base system, model library system, database system, geometric shaping system, and the interfaces of ANSYS and pro/E, which is shown in Figure 2.

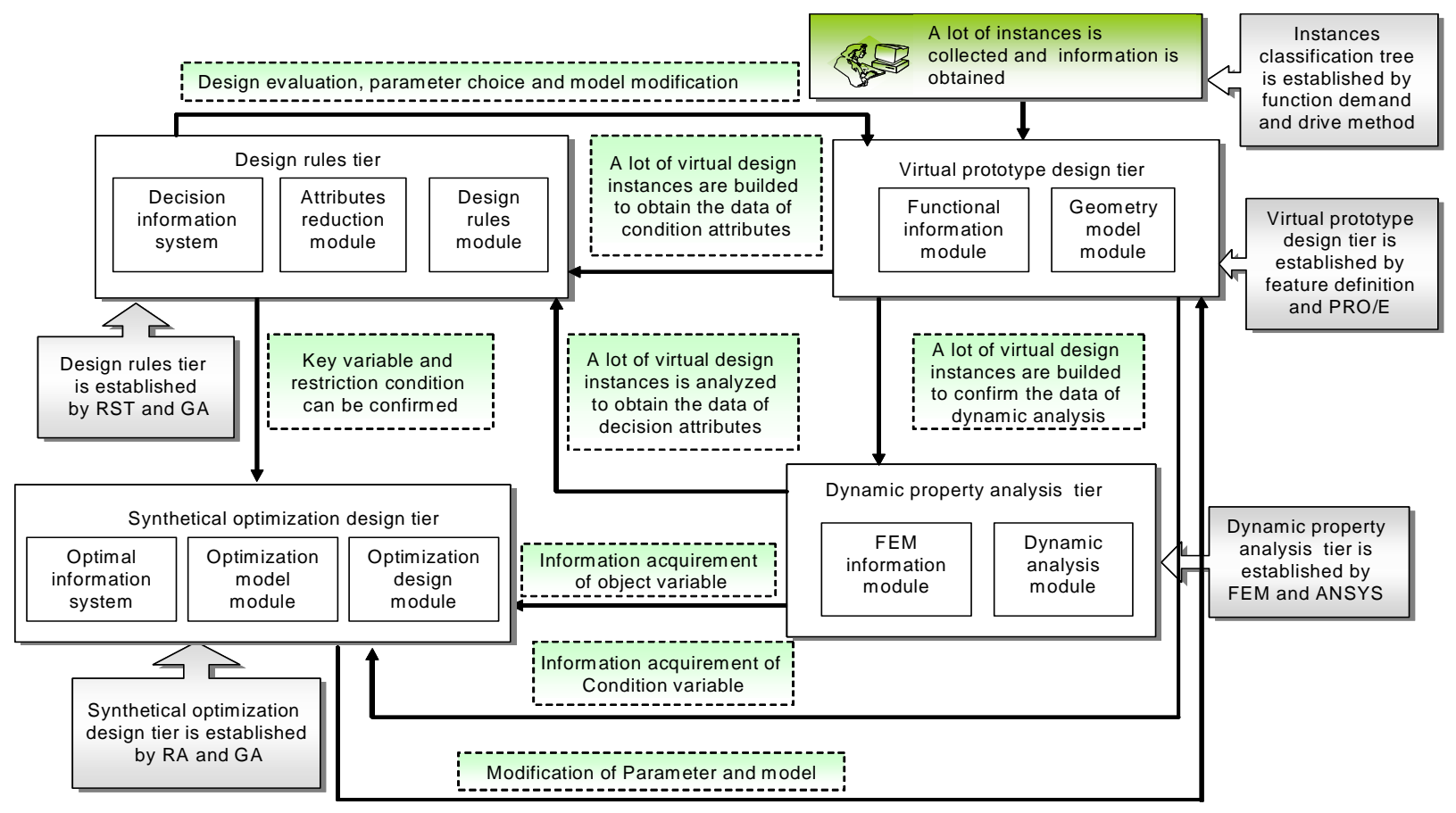

Figure 1 Method and frame of integrated system for the synthetical optimization design of micro-components

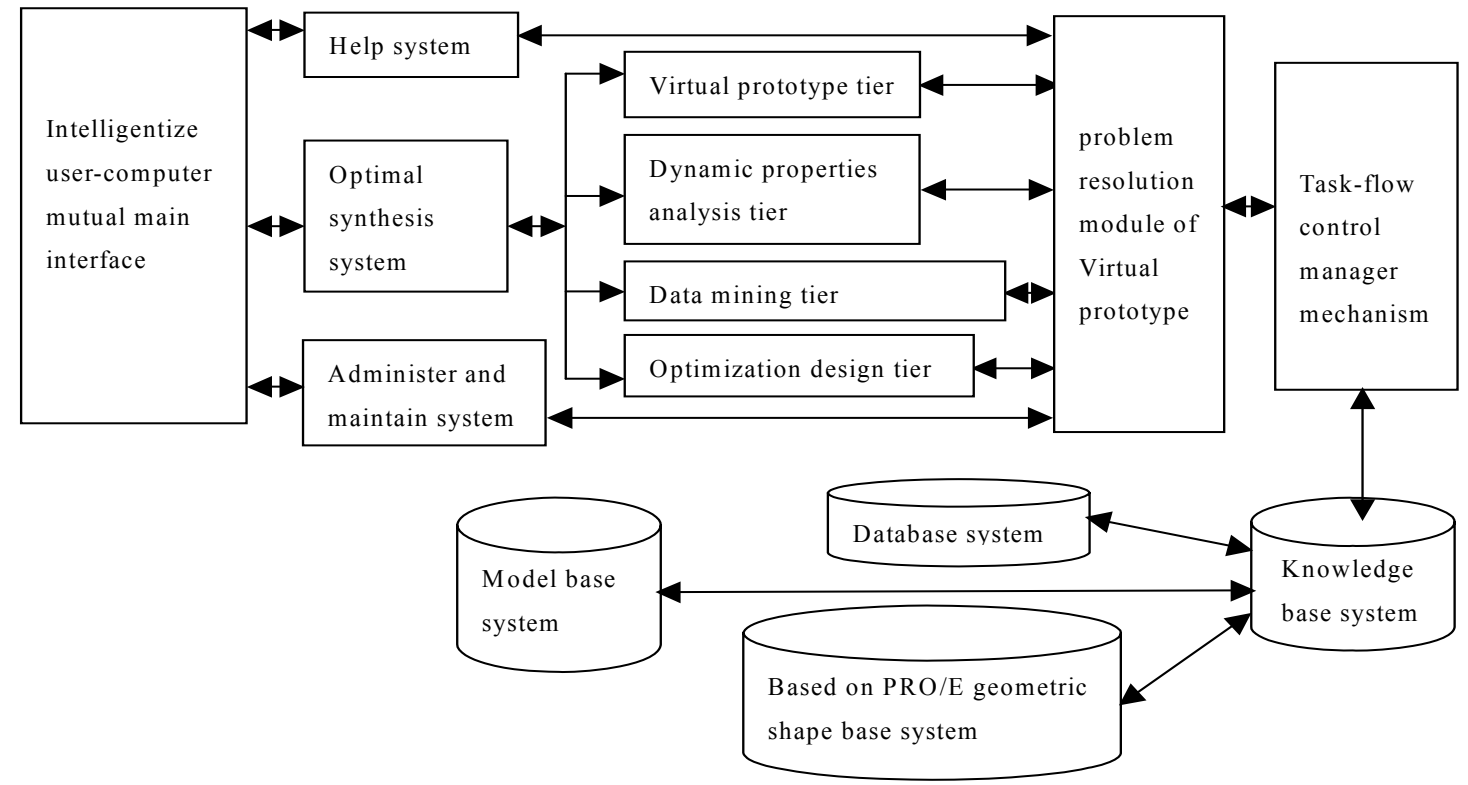

Figure 2 IDSS Architecture of optimal design synthesis for micro-component

\subsection{Prototype system development}

Based on the methods and architecture mentioned above, activity model of whole process is established by UML; the integrated platform of the prototype is developed based on Java; Jess is adopted as a reasoning tool for knowledge modeling and reasoning system; JDBC technology is used to implement the connection between java programs and SQL Server database. IDSS is used to integrates the different functional modules, interfaces of 
ANSYS and PRO/E, database etc in process of prototype tool development, and meantime Task-flow control mechanism is used to decide task courses and control the decision orders in iterative and repeating process of synthetical optimization design, which solves the key problem of data exchange and model conversion availably. Based on the above running mechanism and procedure, a CAD-based intelligent and integrated system for the synthetical optimization design of micro-components is developed, which is shown in Figure 3.

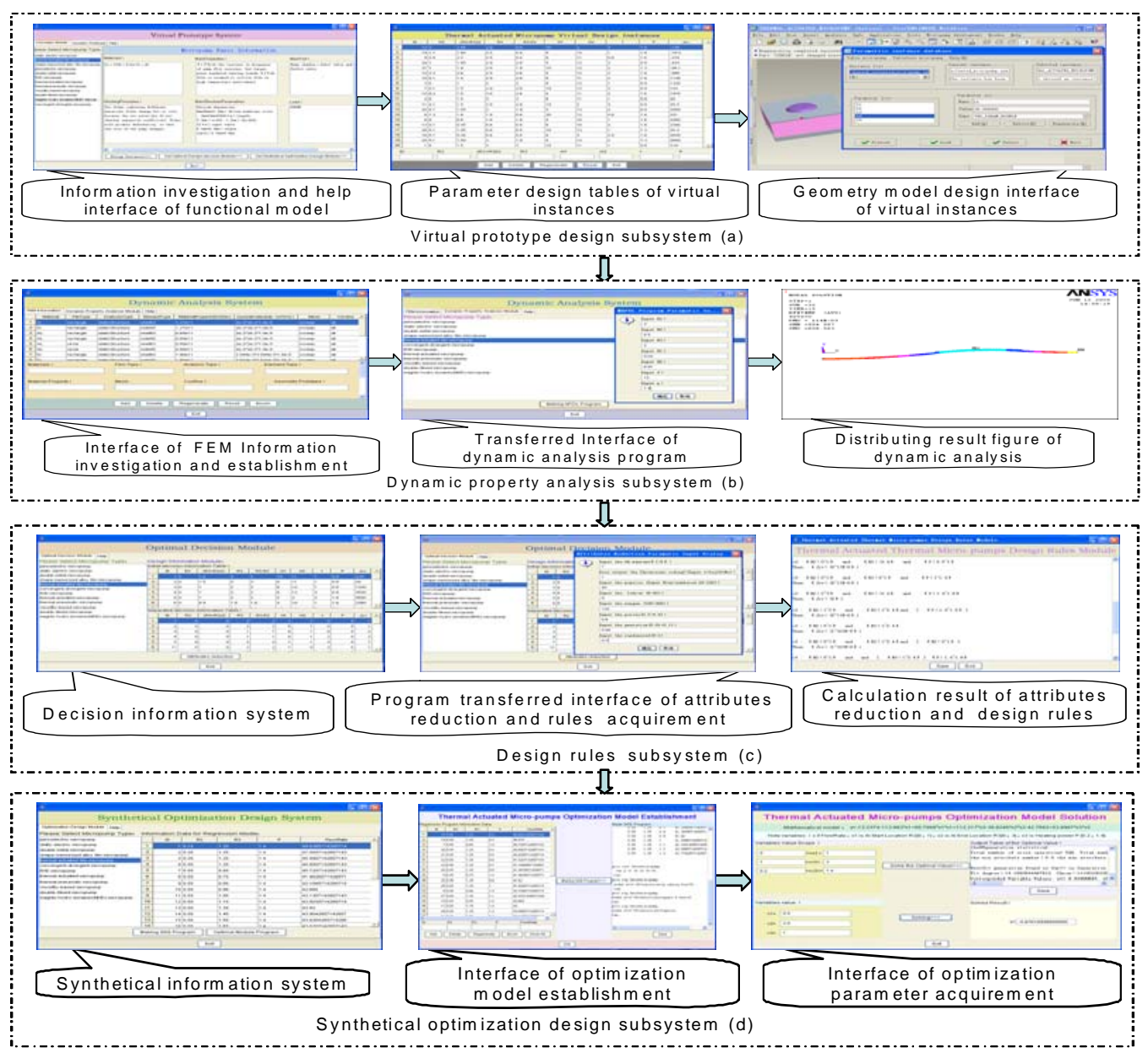

Figure 3 System interface for the synthetical optimization design of micro-components

\section{Case study}

Based on developed a prototype tool of synthetical optimization design for micro-components, we select thermal actuated micro-pumps as

\subsection{The information acquirement of thermal actuated micro-pumps}

\subsubsection{The virtual instances establishment}

The functional information model of thermal actuated micro-pumps is established and the corresponding running interface is shown in Figure 3(a). examples to demonstrate above ideas and prototype software. Because the experiment equipment of thermal actuated micro-pump is very expensive, the test data is derived from the experiment research in Tsinghua University ${ }^{[9]}$.

By using the functional information model, 27 virtual instances of thermal actuated micro-pumps were constructed to gain design parameter values of geometry, frequency, power, etc, which can be used for the dynamic properties analysis and the data acquirement of independent variable, as shown in 
table 1 .

\subsubsection{Dynamic properties analysis of coupled- energy-domain}

The dynamic properties analysis module of thermal actuated micro-pumps is established and the corresponding running interface is shown in Figure 3(b). According to the working principle and geometry sculpting of thermal actuated micro-pumps, we can know that the key component affecting the capability of thermal actuated micro-pumps is membrane. In these instances, the efficiency of thermal actuated micro-pump is taken as the optimal object and the efficiency namely flux change of unit power is influenced by the distortion of membrane. APDL program of the dynamic properties analysis of coupled-energy-domain of thermal actuated micropumps is developed to carry on 27 virtual instances analysis and obtain optimal object data. Figure 4 shows the whole process of dynamic properties analysis of a thermal actuated micro-pump which consists of simplification model Figure 4(b), temperature field Figure (c) , stress field Figure 4(d) and result test Figure 4(e). The result of numerical simulation is analyzed and verified with the experimental result published in reference [9].

\subsection{Key variables and restricted condition con-} firming

A lot of data obtained are mined to confirm the number and restricted condition of key variable of synthetical optimization model. The whole procedures consist of three different steps, that is, the decision information system establishment, the attribute reduction and design rules acquiring. Corresponding prototype programs are developed and the running interface is shown in Figure 3(c). The analysis procedure is explained in next section.
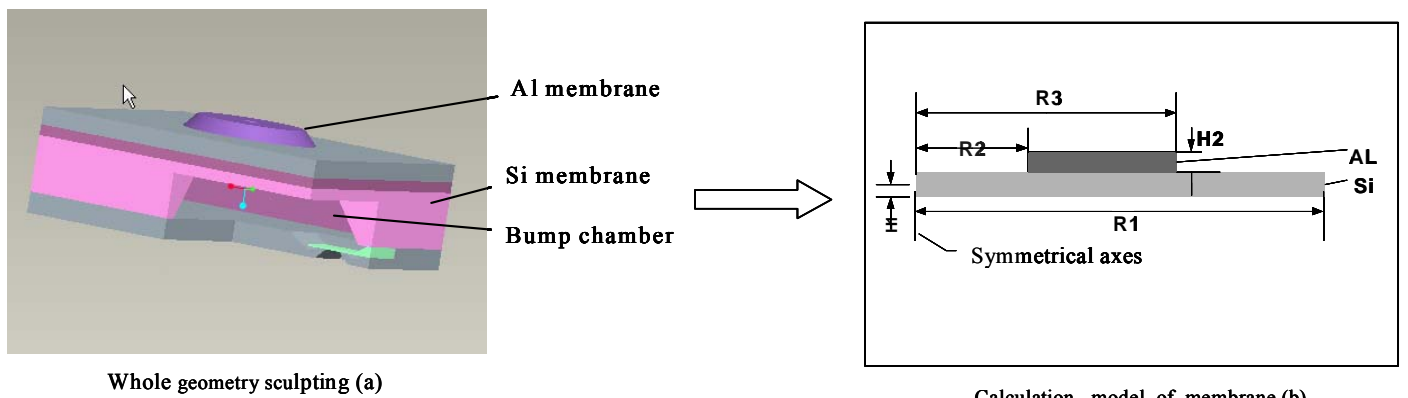

Calculation model of membrane (b)

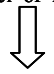

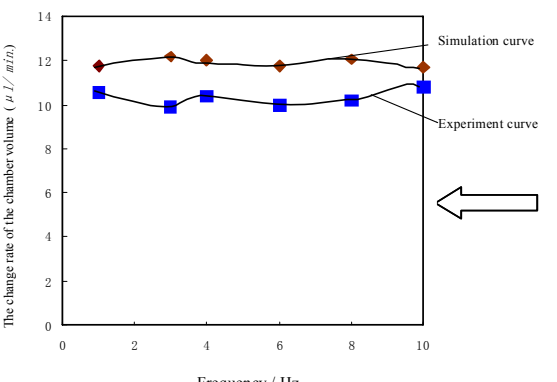

volume change rate vs. frequency (e)

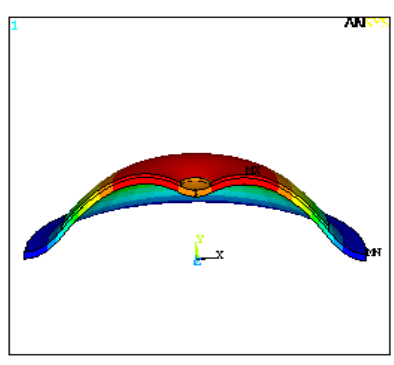

Distortion and stress of membrane (d)

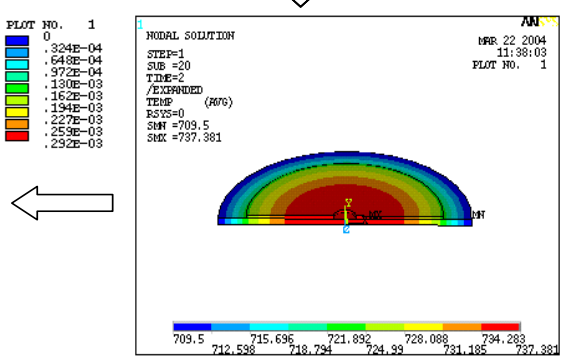

Temperature distribution of membrane in $0.5 \mathrm{~s}(\mathrm{c})$

Figure 4 Dynamic property analysis of coupled-energy-domain of thermal actuated micro-pump

\subsubsection{Decision information system establishment}

1) Establishing attribute set

The optimal objects are defined as decision attributes according to actual requirement, and the initial parameters such as geometry parameters, capa- bility parameters, material information and powers are defined as condition attributes. For the thermal actuated micro-pump, its efficiency is defined as the optimal object. Therefore, the decision attribute is reflected by efficiency, namely, the volume changing of micro-pump antrum denoted as $\triangle \mathrm{V}$, and its 
condition attributes mainly consists of start and end positions of aluminum membrane, width of aluminum ring, thickness of silicon membrane, thickness of aluminum membrane, frequency of calefaction and power of calefaction.

2) Constructing information table.

As mentioned above, by taking advantage of virtual prototy pe subsystem, under the permitting range of its parameters, 27 virtual design instances were set up, which are taken as the data of condition attributes. Then, APDL program developed is used to implement the dynamic properties analysis of coupled-energy-domain and obtain the values of $\triangle \mathrm{V}$, which are taken as the data of decision attributes. The initial decision information of the thermal actuated micro-pump is shown in Table 1. The decision-making information is shown in Table 1. By carrying out discrete operations on the data in table1 using attribute grade value of $1,2,3$, the discrete information can be obtained as described in table2.

\subsubsection{Attribute reduction}

Based on the decision information, the attribute reduction program developed is used to implement the attribute reduction of the thermal actuated micro-pump. The minimal reduction attributes, namely key variables are acquired.

\subsubsection{Optimal decision-making rules acquire- ment}

The Optimal design rule program developed is used to obtain design rules of the thermal actuated micro-pump, the partial design rules obtained are described as follows:

Rule 1: If start position of aluminum membrane is $0 \sim 1 \mathrm{~mm}$ and width of aluminum ring is $2 \sim 3 \mathrm{~mm}$ and power is $1 \sim 1.4 \mathrm{w}$, then $\triangle \mathrm{V}$ is (30-60) $\mu \mathrm{l} / \mathrm{min}$;

Rule 2: If start position of aluminum membrane is $0 \sim 1 \mathrm{~mm}$ and width of aluminum ring is $1 \sim 2 \mathrm{~mm}$ and power is $0.5 \sim 1 \mathrm{w}$, then $\Delta \mathrm{v}$ is $(0-30) \mu 1 / \mathrm{min}$;

Rule 3: If start position of aluminum membrane is $2 \sim 3 \mathrm{~mm}$ and width of aluminum ring is $2 \sim 3 \mathrm{~mm}$ and power is 1.4 1.8w, Then $\triangle \mathrm{v}<0 \mu 1 / \mathrm{min}$.

\subsection{Synthetical optimization design of thermal actuated micro-pump}

By implementing regression analysis operations, the synthetical optimization model is established. Based on the data of virtual instances design, dynamic analysis results, reduction attribute and design rules, further the result of synthetical optimization design is obtained based on GA. Corresponding prototype program is developed and the running interface is shown in Figure 3(d).

\subsubsection{Synthetical optimization model constructing}

Based on the data of minimal attribute in decision information Table 1, the trend carve and unitary regress models of efficient namely objected variable with start position of aluminum, width of aluminum ring and power are established and then these unitary regress models are added to get a nonlinear multi-variable regress model and is carried through linearization. The regressive analysis program of SAS is developed to solve the optimal multi-variable regress model and result is shown in Table 3. The synthetical optimization model is described in details as follows: Objective function: $y=9.4211-40.2992 * x 1+36.7757 *$ $\mathrm{x} 1 * \mathrm{x} 1+17.5732 * \mathrm{x} 2-6.3715 * \mathrm{x} 2 * \mathrm{x} 2+17.997 * \mathrm{x} 3 * \mathrm{x} 3$ Restrained condition: $\quad 0 \leq \mathrm{X} 1 \leq 1, \quad 0.5 \leq \mathrm{X}_{2}-\mathrm{X}_{1} \leq 3$ $1 \leq \mathrm{X} 3 \leq 1.4$ Where, $\mathrm{Y}(\mathrm{X})$ represents the efficiency; $\mathrm{X} 1, \mathrm{X} 2$ and $\mathrm{X} 3$ are start position of aluminum, width of aluminum ring and power; the boundary values of $X_{1}, X_{2}$ and $X_{3}$ mainly depend on design rules. 
Table 1 Initialization decision information table of thermal actuated micro-pump

\begin{tabular}{|c|c|c|c|c|c|c|c|c|c|}
\hline $\mathrm{O}$ & $\begin{array}{l}\text { Start place } \\
\text { (AL) } \\
\text { R2 (mm) }\end{array}$ & $\begin{array}{l}\text { Middle place } \\
(\mathrm{AL})(\mathrm{mm}) \\
(\mathrm{R} 2+\mathrm{R} 3) / 2\end{array}$ & $\begin{array}{c}\text { End place } \\
\text { (AL) } \\
\text { R3 (mm) }\end{array}$ & $\begin{array}{c}\text { Width (AL) } \\
\text { (R3-R2) } \\
(\mathrm{mm})\end{array}$ & $\begin{array}{l}\text { Thickness } \\
\text { (SI) } \\
\text { H1 ( } \mu \mathrm{m})\end{array}$ & $\begin{array}{c}\text { Thickness } \\
\text { (AL) } \\
\text { H2 ( } \mu \mathrm{m})\end{array}$ & $\begin{array}{c}\text { Frequency } \\
(\mathrm{Hz})\end{array}$ & $\begin{array}{l}\text { Power } \\
\text { (w) }\end{array}$ & $\begin{array}{l}\Delta \mathrm{v} \\
(\mu 1 \\
/ \min )\end{array}$ \\
\hline 1 & 0.55 & 1.1 & 1.65 & 20 & 10 & 10 & 1 & 0.5 & 21. 3 \\
\hline 2 & 0.25 & 0.4 & 0.55 & 20 & 12 & 12 & 3 & 0.85 & 20.6 \\
\hline 3 & 0.15 & 0.7 & 1.25 & 8 & 10 & 10 & 5 & 1.1 & 35. 3 \\
\hline$\vdots$ & $\vdots$ & $\vdots$ & $\vdots$ & & $\vdots$ & 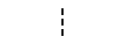 & $\vdots$ & $\vdots$ & $!$ \\
\hline 2 & 0.1 & 1.05 & 2 & 1.9 & 5 & 12 & 8 & 1.6 & 56.9 \\
\hline 7 & & & & & & & & & \\
\hline
\end{tabular}

Table 2 Discrete decision information table of thermal actuated micro-pump

\begin{tabular}{|c|c|c|c|c|c|c|c|c|c|}
\hline $\mathrm{O}$ & $\begin{array}{c}\text { Start place } \\
\begin{array}{c}\text { (AL) } \\
\text { R2 }\end{array}\end{array}$ & $\begin{array}{l}\text { Middle place } \\
\qquad(\mathrm{AL}) \\
(\mathrm{R} 2+\mathrm{R} 3) / 2\end{array}$ & $\begin{array}{c}\text { End place } \\
\qquad \begin{array}{c}\text { (AL) } \\
\text { R3 }\end{array}\end{array}$ & $\begin{array}{r}\text { Width (AL) } \\
\text { (R3-R2) }\end{array}$ & $\begin{array}{c}\text { Thickness } \\
\text { (SI) } \\
\text { H1 }\end{array}$ & $\begin{array}{c}\text { Thickness } \\
\text { (AL) } \\
\text { H2 }\end{array}$ & Frequency & Power & $\Delta \mathrm{v}$ \\
\hline 1 & 1 & 1 & 1 & 1 & 1 & 0 & 0 & 0 & 0 \\
\hline 2 & 1 & 0 & 0 & 1 & 1 & 1 & 0 & 1 & 0 \\
\hline 3 & 0 & 0 & 1 & 0 & 0 & 0 & 1 & 2 & 1 \\
\hline$\vdots$ & $\vdots$ & $\vdots$ & $\vdots$ & $\vdots$ & $\vdots$ & $\vdots$ & $\vdots$ & $\vdots$ & $\vdots$ \\
\hline 2 & 0 & 0 & 1 & 1 & 0 & 1 & 2 & 2 & 2 \\
\hline 7 & & & & & & & & & \\
\hline
\end{tabular}

Table 3 Result data of multi-variable regress model

\begin{tabular}{cccccccc}
\hline variable & $\begin{array}{c}\text { Free } \\
\text { degree }\end{array}$ & $\begin{array}{c}\text { Estimation } \\
\text { value }\end{array}$ & $\begin{array}{c}\text { Standard } \\
\text { error }\end{array}$ & $\begin{array}{c}\text { statistician } \\
\text { measures(T) }\end{array}$ & Pr $>|\mathrm{t}|$ & $\begin{array}{c}\text { Safety } \\
\text { margin }\end{array}$ & $\begin{array}{c}\text { Square deviation } \\
\text { expansion factor }\end{array}$ \\
\hline Constant & 1 & -0.6313 & 0.7534 & -0.84 & 0.4170 &. & 0 \\
variable & & & & & & \\
t11 & 1 & -40.2992 & 1.3579 & -29.68 & $<.0001$ & 0.0412 & 24.2715 \\
t12 & 1 & 36.7757 & 1.5251 & 24.11 & $<.0001$ & 0.0428 & 23.3756 \\
t21 & 1 & 17.5732 & 0.9290 & 18.92 & $<.0001$ & 0.0203 & 49.3721 \\
T22 & 1 & -6.3715 & 0.3849 & -16.55 & $<.0001$ & 0.0204 & 49.0076 \\
T32 & 1 & 1.7997 & 0.0483 & 37.24 & $<.0001$ & 0.7198 & 1.3894 \\
\hline
\end{tabular}

$(\alpha=0.05 ; \quad F(6,23)=980.21 ; \quad p<0.001)$ 


\subsubsection{Result and discussion of synthetical optimization design}

According to the above mathematical model of synthetical optimization of thermal actuated micro-pump, we develop the model solution program by use of GA. By use of the model solution program developed, we get the optimization design result, which is inherence frequency is $3.3 \mathrm{~Hz}$, start position of aluminum is $0.01 \mathrm{~mm}$; width of aluminum ring is $1.37 \mathrm{~mm}$; power is $1.4 \mathrm{~W}$, the maximal efficiency is $56.78 \mu 1 / \mathrm{min}^{*} \mathrm{~W}^{-1}$, which is shown in Table 4 . The research indicates that the curve of efficiency with power from synthetical optimization design model is generally conformed to the result produced from experiment [9], which is shown in Figure 5(a). It can show that synthetical optimization model established is reasonable and feasible. Furthermore, by comparing simulative curve 1 , simulative curve 2 and optimal simulative curve in Figure 5(b), we can find that the maximal efficiency is also related with the start position of aluminum and width of aluminum ring. When the start position of aluminum is nearly $0 \mathrm{~mm}$ and width of aluminum ring is $1.37 \mathrm{~mm}$, the efficiency is preferable.

Table 4 Synthetical optimization design of thermal actuated micro-pump

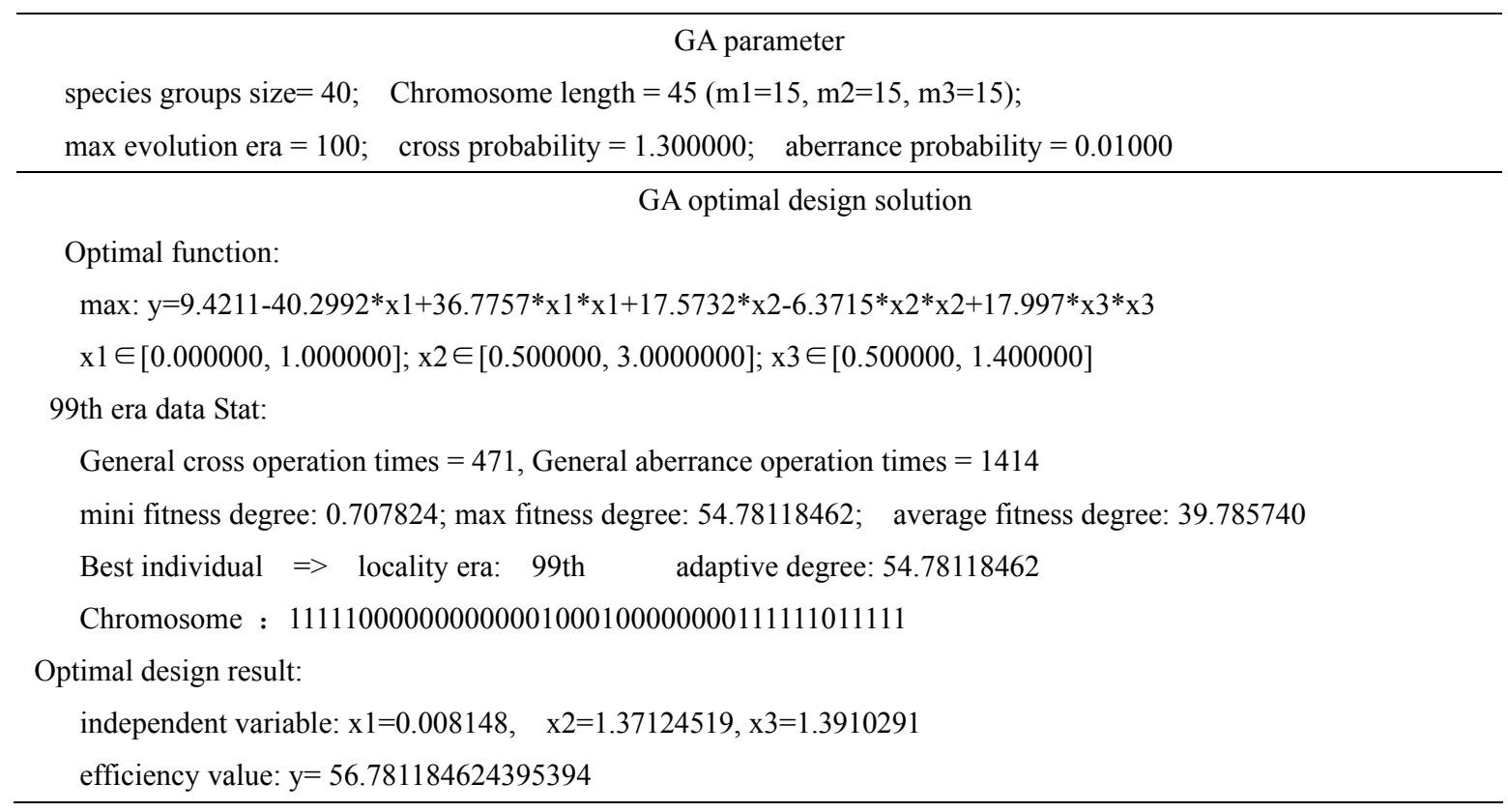

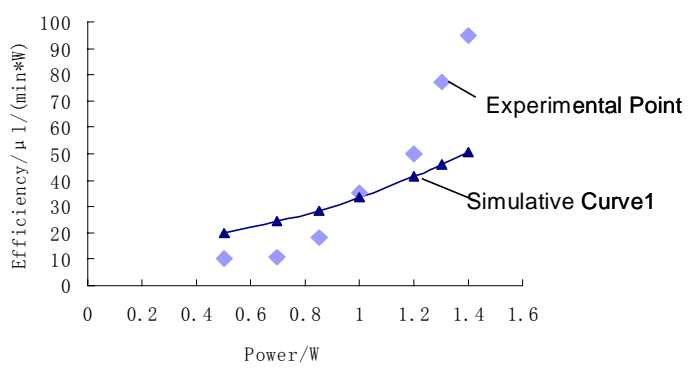

Contrast curve of experiment with simulation (a)

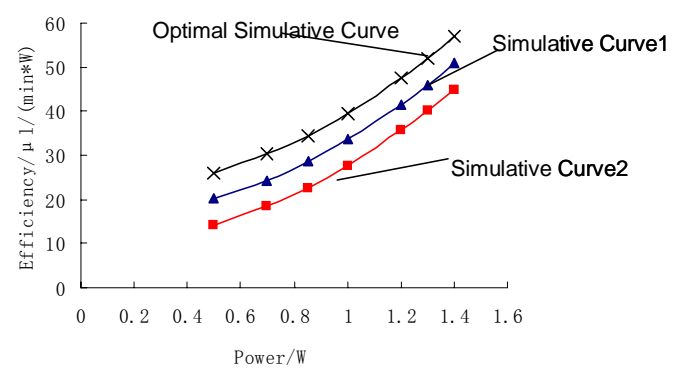

Contrast curve of different variables value (b)

Figure 5 Contrast curve of experiment with simulation of thermal actuated micro-pump 


\section{Conclusions}

A new approach about the synthetical optimization design of micro-component is presented in this paper, which incorporates VP, FEM, RST, RA, GA and prototype system software is developed. The synthetical optimization design of a thermal actuated micro-pump is applied as a case based on the above basic theories and prototype software. The results indicate that the approach is highly valid and feasible, which can be used to the synthetical optimization design of new micro-components or modify the already existing micro-components structure to settle the bottleneck problem of quality fallibility and low efficiency of micro-component design.

\section{Acknowledgments}

This work is supported by National Natural Science Foundation of China $(50375118,5014006)$

\section{References}

[1] M.Shavezipur, K.Ponnambalamb, "A probabilistic design optimization for MEMS tunable capa- citors" , Microelectronics Journal, Vol.39, pp. 1528- 1533, 2008.

[2] P.Schneider, A.Schneider,P.Schwarz, "A modular approach for simulation-based optimization of MEMS", Microelectronics Journal, Vol. 33, pp. 29-38, 2002.

[3] Z.Juneidi, "MEMS synthesis and optimization", Proceedings of SPIE - The International Society for Optical Engineering, 4408:159-164, 2001.

[4] S.E.Lyshevski, "Optimal structural synthesis, modeling, and control of micro-mechatronics sys- tem", Mechatronics, 11(2), 837-851.M.F, 2001.

[5] M.F.Aly, E.Ng, S.C.Veldhuis, "Prediction of cutting forces in the micro-machining of silicon using a "hybrid molecular dynamic-finite element analysis" force model", International Journal of Machine Tools \& Manufacture, 2006(46): 1727-1739.

[6] A.tthew, R.Michael, "Reliability-based analysis and design optimization of electrostatically actuated MEMS", Computers and Structures,
2004(82): 1007-1020

[7] H.Li, Q.X.Wanga, "A variation of local point interpolation method (vLPIM) for analysis of microelectromechanical systems (MEMS) device", Engineering Analysis with Boundary Elements, 2004(28): 1261-1270

[8] L.Y.Zhai, L.P.Khoo, S.C.Fok, "Feature extraction using rough set theory and genetic algorithms an application for the simplification of product quality evaluation", Computer \& industrial Engi- neering, 2002, 43,661-676.

[9] Z.Z.Yin, N.Xu, J.T.Pang etc, "Experimental study on thermal actuated micropump", Journal of Functional Materials and Devices, 2000, 6(2): 65-70. 